OPEN ACCESS

Edited by:

Francesca Fulminante University of Bristol, United Kingdom

Reviewed by:

Katarzyna Ujma-Wasowicz, Silesian University of Technology, Poland

Stephen Collins-Elliott, The University of Tennessee, Knoxville, United States Rafael Scopacasa Federal University of Minas Gerais, Brazi

*Correspondence: Andrew H. F. Cabaniss ahfc@umich.edu

Specialty section: This article was submitted to Digital Archaeology, a section of the journal Frontiers in Digital Humanities

Received: 24 November 2018 Accepted: 22 May 2019

Published: 11 June 2019

Citation:

Cabaniss AHF (2019) More Real Than Ideal: Household and Community Diversity at Metapontum, South Italy. Front. Digit. Humanit. 6:11. doi: 10.3389/fdigh.2019.00011

\section{More Real Than Ideal: Household and Community Diversity at Metapontum, South Italy}

\author{
Andrew H. F. Cabaniss* \\ Interdepartmental Program in Classical Art and Archaeology, University of Michigan, Ann Arbor, MI, United States
}

Empirical studies of ancient cities must break down communities into their component parts, but frequently encounter difficulty with the scarcity of excavated domestic structures (e.g., Kramer, 1982, p. 673). I introduce to the archaeological literature the entropy estimating statistical bootstrap (EESB), a tool developed in information theory and computational social science by DeDeo et al. (2013) which provides a way to assess how representative a small dataset is of a parent population, categorized according to some useful typology. This method can be used to decide when small datasets can add further detail to our quantitative studies of archaeological settlements or when they need to be rejected as too small. I then illustrate its uses within the context of urban demography by examining the distribution of house forms to calculate household characteristics specific to Metapontum, an ancient Greek city. Future applications will include building larger urban datasets that are empirically grounded in the specific evidence for each community, facilitating the work of research programs such as urban scaling.

Keywords: urbanism, diversity, entropy, households, ancient Greece, communities, metapontum

\section{INTRODUCTION}

To make sense of urbanism requires a study of communities and of small groups like households. Discussions of ancient urbanism in the classical Mediterranean frequently focus on institutional macroscales of analysis to the detriment of individuals, partly because well-published evidence for households and burials are unevenly distributed. Their scant traces are frequently difficult to interpret in isolation without understanding their relation to the absent majority of material remains. Making rigorous use of small datasets of houses is required to grapple with the full richness of the archaeological traces of ancient cities.

In this paper, I examine the rural domestic remains of the city of Metapontum in Southern Italy in order to explore its urban demography and social diversity. In part, this is because thousands of farms are known from the well-documented countryside through surface survey, yet only a handful of these have been excavated (Carter, 2011). In order to check whether the small sample of excavated farmsteads is consistent with the less well-known survey sites, I introduce into the archaeological literature the entropy estimating statistical bootstrap (EESB) (DeDeo et al., 2013). The EESB can be used to assess whether a categorized sample is consistent with a similarly categorized source population. I provide an example to clarify how it works, and then provide a toy model of houses in a fictitious community that would be rejected by this method because of an overly small sample size for too diverse a community when described by a particular typology. 
For Metapontum, I use the EESB to show that the sample of 11 rural houses from the 6th through 3rd centuries BCE appears to be consistent with the inferred frequency of different types of houses present in the ancient city when the types are defined in a socially meaningful way. In short, passing the EESB test makes a demographic analysis of households at Metapontum feasible, despite the small sample size. I then estimate the average characteristics of these households and an overall mean household size for the city. Statistical tests and calculations based on small samples can extend current methods for the quantitative study of ancient urbanism by providing a more detailed empirical record unique to individual cities such as Metapontum. It is hoped that this method will aid studies that attempt to put ancient Mediterranean urbanism into quantitative comparative frameworks like urban scaling (Hanson and Ortman, 2017). The EESB enables urban scaling theory to proceed at the level of populations as it was originally framed (Bettencourt, 2013), and in general gives the diversity of ancient cities the chance to speak for themselves within large-scale studies.

\section{Houses and Families at Metapontum}

The community at Metapontum, an ancient Greek city in the south of the Italian peninsula, has an extensively documented material record because of the density of excavations and surveys throughout the city's hinterland. The record of rural housing provides an opportunity to study a classical Mediterranean urban community and assess whether the published houses offer a representative glimpse into the demographic diversity of its inhabitants.

Much as in modern cities where the urban population is defined based on commuting patterns and social interactions (Bettencourt et al., 2010), so in many ancient Greek cities city folk had country houses in which they lived full- or parttime while engaging with the political, economic, religious, and social life of the city. Carter has argued that at Metapontum civic infrastructure was explicitly expanded to enfranchise the rural inhabitants and include them in political decision making (Carter, 2006, p. 204-24). It is important to remember these rural dwellings in our demography, and in the case of Metapontum they are more fully published, making it easier to consider how house architecture reflects household priorities, which in turn suggest demographic differences between households. While the presence and documentation of an urban grid have influenced our view of Metapontum just like many ancient Greek cities, there is also considerable evidence for the importance of the countryside as a residential option for the urban population.

\section{History of Metapontum}

Metapontum, or Metaponton, emerged in the eighth century BCE through violent conflict, persistent trade, and other intense modes of interaction at the intersection between indigenous, colonial, and trading populations (Carter, 1980; De Siena, 2001). Over a half century, the ancient Greek community disrupted the existing way of life for coastal and foothill Italic populations through aggressive raiding and territorial expansion, causing the abandonment of settlements in and around the future site of the city (Carter, 1980, 2006, p. 197-203; De Siena, 2001). Networks of sanctuaries and villages expanded into the countryside during the 6th century as the city center itself first defined its form with an urban grid, communal architecture, and civic temples (Osanna, 1992, p. 45-46; Carter and Prieto, 2011, p. 559-67; Carter, 2006, p. 204-14).

The Archaic boom of the city preceded an uneasy period of growth and contraction. Early fifth century land reclamation projects encouraged an expansion by farmers onto new lands, but a half century later these farms lay abandoned and new civic constructions remained without repairs for years (Carter, 2006, p. 214-24; Mertens, 1999). Individuals likely moved back within the city walls full time, or alternatively left the area entirely because of neighboring political instability. The Lucanians who began to move into this area may have responded to or caused some of these disruptions, but ultimately benefited from a city eager to have its countryside resettled (Carter, 2006, p. 218-32).

Fourth century Metapontum's investments in the future of the town did not provide stability in an increasingly Roman Italy: following their alliance with Pyrrhus against Rome, a military camp was imposed on the city, at which point the population began to emigrate en masse (De Siena and Giardino, 2001). Opposing the Romans during the Second Punic War led to the city being carved up into farmland for massive estates that would come to dominate the Roman Italian agricultural system.

The community at Metaponto thus ebbed and flowed into its countryside as local policies, foreign powers, and homegrown responses to external circumstances alternately pushed the city down different developmental paths. As is suspected for many ancient Greek cities, the social community frequently extended beyond the walls of the physical city itself, incorporating rural inhabitants into the political and social apparatus of the urban community (Carter, 2006; Hansen, 2006a, p. 101-5). The composition of this community is visible through the varied architectural properties of farmhouses whose inhabitants were part of the city, providing a realistic test for the models and problems of quantitative urban studies based on archaeological data and a useful case study for understanding demography and social diversity at an urban settlement.

\section{Farmhouses and Their Variation}

Although discussions of ancient Greek cities' social history often make use of large social categories such as rural inhabitants and urban residents, these labels mask significant variability. House architecture varied greatly at Metapontum, reflecting a shadow of the social diversity of these buildings' inhabitants (Lanza Catti et al., 2014b). Some houses are single structures, while others are groups of buildings; some farms have towers incorporated into their design, while others do not; still others utilize an entirely or partly enclosed courtyard as a transition between rooms, while others use interior hallways and multiple exterior doors to facilitate communication. Architectural variation is not an idle difference to notice, as each of these organizational differences supports a range of social and cultural practices that facilitate the daily life of the household, and thus bear witness to the household diversity of rural inhabitants (Kent, 1990; Nevett, 2007b; Westgate, 2015). Architecture does not wholly reflect intent or constrain action, however, and diversity in household 
composition and organization will always supersede material variation (e.g., Nevett, 1999).

The integration of a courtyard, the segmentation of space into separate buildings, and the investment in towers all provide loci for the display and storage of wealth as well as opportunities for privacy and oversight to be built into the walls of a structure. Courtyards have the potential to provide privacy from outsiders for open air activities that require direct light and ventilation, but also facilitate control within the house, as rooms facing a courtyard can provide a panoptic view of tasks and movements between rooms (Nevett, 1994, 2007b; Foxhall, 2009; Westgate, 2015). Particularly in rural settings, the privacy of the family overall may be less important than the visibility of the members of the household who were perceived to be vulnerable (Nevett, 2005; Llewellyn-Jones, 2007).

Segmentation of spaces, both into multiple rooms and into different buildings may indicate an investment in infrastructure to oversee labor conducted by dependents, servants, or slaves. While cross-culturally segmentation in housing is associated with wealth, in the ancient Greek cultural context it has further been linked to the increasing presence of non-free dependents such as slaves and servants in elite houses whose menial labor needed to be segregated from the free family (Jameson, 1990; Kent, 1990; Westgate, 2015). Incorporating multiple rooms also enabled the flexible gendered use of space throughout the day and as visitors came and went (Nevett, 1994; Westgate, 2015).

Towers in houses reflect concerns about the protection of wealth and appear as a phenomenon across the Mediterranean during the fourth century BCE. They are especially common in intensive agricultural regimes where the storage of cash crops and the large-scale use of enslaved agricultural laborers went hand in hand (Morris and Papadopoulos, 2005). Regardless of whether particular rooms were used by freed or unfree people or what forms of wealth were stored in locked rooms, architectural developments at the level of individual farmhouses indicate the socioeconomic diversity present in the rural community at Metapontum and the varying strategies individual households adopted to manage and utilize their present resources (Carter, 1990; Nevett, 2005, 2007a).

Following the work of Carter, Lanza Catti, Swift, and others studying Metaponto, I gathered architectural descriptions and chronological information on 11 houses (Table 1) (Carter, 2006, p. 136-53; Lanza Catti et al., 2014b). These houses are primarily published architecturally, with the plan, types of rooms, major architectural features, and occasional finds emphasized. Thus, courtyards, towers, and the segmentation of space into buildings are the most reliable features documented for each household, and are the focus of this study. Investment in processing or storage installations, assemblages of food or textile production implements, and the arrangement of activity areas in space could also be examined for the same purpose, but were not readily available for the houses considered in this study.

The dates for these 11 houses range between the 6th and 3rd centuries BCE, with many of them broadly dated. Following standard practice for comparative urban studies, this information would normally be used synchronically by assuming that the houses present a typical view of the range of houses, and by extension the material traces of households. It is also a necessary assumption in many cases, as otherwise it is difficult to gather sufficient evidence about demography (Bagnall and Frier, 1994, p. 31-52). If we make this assumption, it is possible to classify rural houses at Metapontum according to an architectural typology that distinguishes between the presence and placement of the courtyard in each house and the presence of a tower, as these are likely socially meaningful following the discussion above. It is also possible to distinguish farmhouses by the number of distinct buildings on the same plot or sharing a courtyard. The way each house was assigned to a different category can be seen in Table 1. While this study limits itself to a synchronic approach, a diachronic approach would provide another extension to existing urban scaling studies in the Mediterranean that could be carried out in future work.

Eleven houses categorized into four architectural types or three different numbers of buildings is not a large sample to investigate, but studying empirical data at the household scale makes it impossible to throw out samples solely because they are small. It is necessary to distinguish when small samples sizes are likely to be representative of the unobserved community and when they are too small to meaningfully represent the community's variability. In short, increasing the detail of studies of ancient Mediterranean urban studies requires consistent measures of diversity that can suggest when a small sample size captures the breadth of material culture from a community and when it is too small.

I believe this is possible by estimating the diversity of houses classified according to a socially-meaningful typology within a community using a statistical tool developed by DeDeo et al. (2013). By assessing whether a sample closely matches the diversity of its parent population, it is possible to reject a small sample as being inadequately informative when classified in a given way, or to accept the possibility that it is representative. As with all hypothesis testing, we can only nullify the assumption that a sample is representative, but this nevertheless provides a useful check on which small datasets are good to use in community demography and which are not.

\section{MATERIALS AND METHODS \\ Measuring Diversity}

Measuring diversity, by which I mean the total number and frequency of distinct observed types, requires a well-structured methodology. For categorical data, including the frequency of household structures or house layouts, there is no assurance that an archaeologist has observed all categories of material in a given sample for a particular way of dividing up material. To compare one assemblage with another, diversity has been dealt with by subsampling from larger distributions, a procedure which tests whether assemblages of different sizes are comparably diverse by checking how many types would show up in the largest sample if the sample were smaller (Kintigh, 1984). This makes it difficult to check whether our largest sample of a given phenomenon is representative of the unknowable parent population, however. These checks of relative diversity also do not address whether our 
TABLE 1 | Rural houses at Metaponto.

\begin{tabular}{|c|c|c|c|c|c|}
\hline House & Chronology & Buildings & Court? & Tower? & Typology \\
\hline Fattoria Fabrizio & 2nd half $4 \mathrm{c}$. & 1 & None & None & No court \\
\hline Fattoria Stefan, Contrada Campagnolo & 2nd half $4 \mathrm{c}$. & 1 & Center & Present & Central court w/ tower \\
\hline Pizzica Pantanello Farmhouse & 1st half $3 \mathrm{c}$. & 1 & None & None & No court \\
\hline Cugno del Pero, Bufalara & 2nd half $6 \mathrm{c}$. & 1 & None & None & No court \\
\hline San Biagio sanctuary farmhouse & Late $3 \mathrm{c}$. & 2 & Off-center & None & Off-center court \\
\hline Ginosa Marina (Archaic 1), Pantano & 2nd half $6 \mathrm{c}$. to $1 \mathrm{st}$ half $5 \mathrm{c}$. & 1 & None & None & No court \\
\hline Ginosa Marina (Archaic 2), Pantano & 2nd half $6 \mathrm{c}$. to $1 \mathrm{st}$ half $5 \mathrm{c}$. & 1 & None & None & No court \\
\hline Ginosa Marina (Archaic 3), Pantano & 2nd half $6 \mathrm{c}$. to $1 \mathrm{st}$ half $5 \mathrm{c}$. & 1 & None & None & No court \\
\hline Proprieta Morlino, Pantanello & 2nd half $4 \mathrm{c}$. to mid $3 \mathrm{c}$. & 1 & Center & None & Central court \\
\hline Cappa d'Amore, Saldone & $6 \mathrm{c}$. and $4 \mathrm{c}$. & 1 & Center & None & Central court \\
\hline Musillo, Saldone & $4 \mathrm{c}$. to $1 \mathrm{st}$ half $3 \mathrm{c}$. & 3 & Off-center & None & Off-center court \\
\hline
\end{tabular}

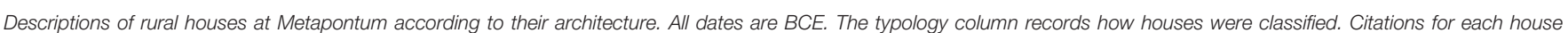

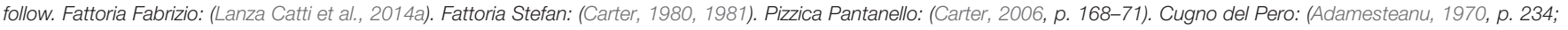

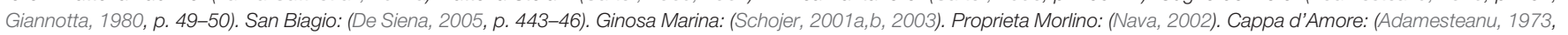
p. 55). Musillo: (Uggeri, 1969; Adamesteanu, 1973, p. 56; Notario, 2001).

typology itself may be an inadequate descriptor of the material record (Cabaniss, in preparation).

To better illustrate the problem, I'll introduce a toy example. Imagine that a group of graduate students working late in an office decide to open a variant of Scrabble in which players create words using letters printed on wooden tiles. In this particular variant, each letter appears on exactly five tiles. If a few of the tiles are missing, as often happens, someone may propose the well-intentioned but tedious idea of counting all the tiles to assess which ones are missing. While this may be feasible, it may also be impractical to check all the tiles because of constraints on time (in addition, archaeologically speaking, to constraints on funding, cultural heritage priorities, etc.). Instead, it will be easier to count and sort a sample of the tiles, as long as there exists a methodology to link this smaller sample to the total population. Arbitrarily, the graduate students may decide on a given number to count, say forty. From this largest sample it will always be possible to check whether smaller samples are consistent, but a relative methodology like Kintigh's described above will never reveal whether the smaller tile set is consistent with a distribution of all 26 letters in the alphabet.

Moving from methods that compare diversity between a small sample and a large sample to methods that compare a sample and its unobserved source population requires adopting both a measure of diversity that doesn't depend on the size of the largest sample and a different subsampling strategy. Information theory provides the absolute measure called entropy that describes how well-distributed types are within a sample and how many types there are (Shannon, 1948). Entropy has an infrequent history of use in archaeology, as in many situations it combines two variables that are best kept separate, namely inequality and heterogeneity (Justeson, 1973; Dickens and Fraser, 1984; Benco, 1989). Mathematically it is defined as the negative of the average base- 2 logarithm of a probability distribution, where the distribution refers to the chance of observing a given outcome, such as the chance of randomly drawing a tile with a given letter from a Scrabble box (Equation 1). Effectively, entropy contains the average size in bits (ones and zeros) required to optimally encode the output of the distribution, or alternatively how unlikely each individual category is to be observed, again in bits. For a typology with $k$ total categories, the entropy is maximized when each category is equally likely, at which point it takes the value of $\log _{2} k$. This makes it a useful way to measure diversity in order to compare samples regardless of their size, as its value depends on the number of types and their relative frequency, rather than on the largest sample observed, removing the ultimate constraint in Kintigh's framework that only lets us compare from bigger samples down to smaller samples.

$$
H(p)=\sum_{i=1}^{k}-p_{i} \log _{2} p_{i}
$$

A further extension is to draw subsamples that are the same size as the original sample. While unintuitive, this bootstrapping procedure creates new samples of the original sample size and can thus test congruity between the original sample and estimates drawn from it. This is the EESB proposed by DeDeo et al. and implemented in the python library THOTH (DeDeo, 2013; DeDeo et al., 2013). The logic behind this procedure works as follows for the case of our Scrabble tiles (Figure 1). Having already drawn a sample of forty tiles from the Scrabble box, we construct new datasets that are similar to the original data by repeatedly sampling randomly with replacement. For each new dataset we wish to make, we draw one tile from our group of forty, record the letter on it, and return the tile back to our sample, until we have repeated this forty times. We now have a list of letters that is the same size as our sample, but on average different in key ways: letters that only appeared on one tile in our sample are very likely to be missing, while letters that appeared on multiple tiles in our sample are likely to be represented more frequently. When a letter completely drops out of this new sample, that type is no longer observed. Each time that a letter drops out and other types become more frequent, the entropy of that dataset will be lower than the entropy of our original sample. We can 


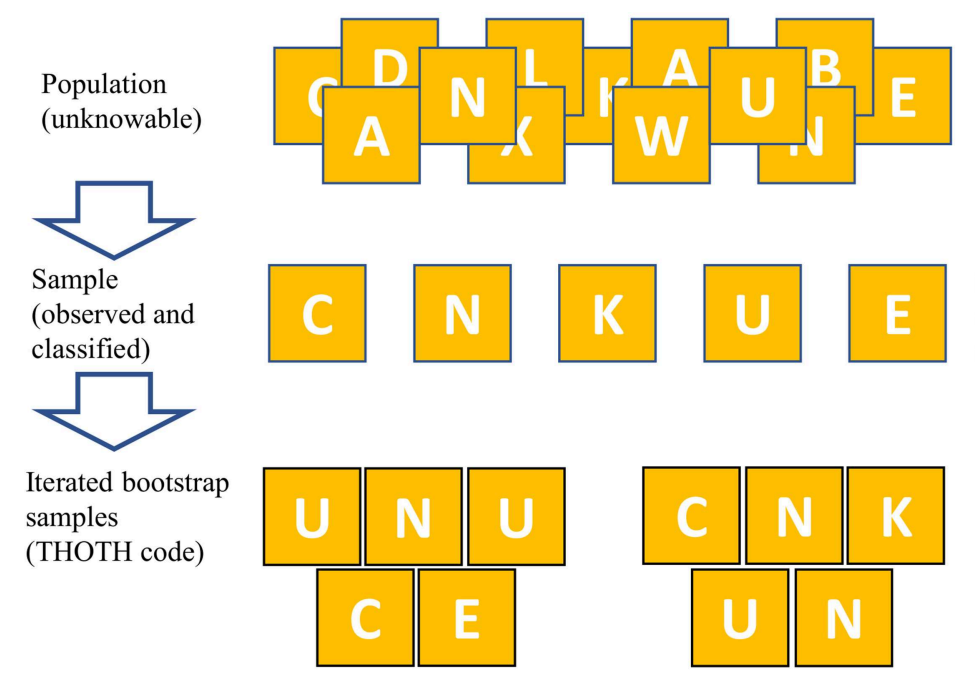

Population

entropy estimated

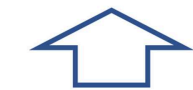

Sample entropy

compared to

subsamples

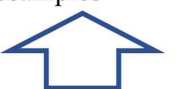

Entropy estimated

for each

subsample

FIGURE 1 | A graphical depiction of the Scrabble example distinguishes between the population (the Scrabble box), the sample (the set of tiles counted), and the iterative subsamples (the artificial datasets made based on the sample). The population is sampled at first, and then the EESB iteratively resamples the sample to produce numerous distributions similar to the original sample through the process called bootstrapping. These then inform our estimates of the bias between the sample and the subsamples, which in turn informs our estimate of the bias between the diversity of the sample and the diversity of the population, classified by a given typology.

then note the decrease in entropy between our original sample of tiles and our new artificial sample that we generated randomly with replacement.

Repeating this procedure thousands of times, we can estimate the systematic decrease in entropy between the original sample and the newly generated samples. Assuming that our original sample of forty tiles was effectively selected from all the tiles in the Scrabble box in a similar way, this systematic decrease in entropy provides a good estimate of how much less diverse our sample of forty tiles was compared to the total set of tiles in the box. If this difference is large, it suggests that our real sample of tiles doesn't capture the diversity of all the tiles in the box, since on average our artificial datasets based on our real sample don't capture the diversity of the sample. If this difference is small, it suggests that our sample reflects the diversity of the population well, since our artificial samples reflected the diversity of our real sample.

In effect, the EESB describes how different our sample of tiles is from the population in the box in terms of the observed frequency of letters. If the two differ radically from each other, a large difference in entropy would be expected, effectively indicating a lack of representativeness based on the poor correspondence between the entropy of artificial datasets drawn from the sample and the sample itself.

For our graduate student friends, this means that they can decide to sort and count a smaller group of tiles and then calculate how much smaller the entropy is compared to what they expect, namely how much diversity, inequality, or heterogeneity is missing from their sample. By comparing this EESB estimate with the expected value of an even distribution of the alphabet, which would be $\log _{2} 26 \approx 4.7$, the graduate students can assess whether the population entropy estimated from their small sample is consistent with the entropy for an even distribution over the letters of the English alphabet.

For archaeologists interested in making inferences about the diversity of collections of archaeological entities such as houses, the EESB provides a way to assess how well the entropy of the observed sample represents the unobserved population. Future statistical work will focus on determining what constitutes a sensible cutoff for representativeness. As a simple heuristic, however, a sample can be rejected if the estimated population entropy is greater than the maximum entropy achievable in a given typology. The maximum entropy possible for a typology with $k$ categories is reached when each type is equally common, reaching a maximum value of $k$. If the estimate of the population entropy is less than this maximum, the small sample categorized according to that typology appears to be consistent with the overall population categorized by the same typology. If the EESB average is higher than this upper limit, however, it would suggest that there are further missing categories that the archaeologist did not observe, as the population entropy is higher than the maximum possible entropy of this typology. A high estimated population entropy implies that the sample is too sparse given the typology under consideration, and either more data must be collected or the typology must be changed to better mesh the archaeological data with the research question. This test only catches one type of error, and future statistical work is needed to better distinguish other types of under-sampled distributions from well-sampled ones (Cabaniss, in preparation).

\section{Experimental Demonstration}

To demonstrate the method, I generated artificial data sets that attempt to capture the effects of different sizes of typology, different structures of samples within these typologies, and 
different samples sizes. In order to generate these data sets, I created categorical distributions with the number of categories ranging between 2 and 10, making 10 different distributions for each number and thus 90 total. These were drawn from a uniform Dirichlet distribution, a common way of generating random numbers that correspond to the probability of observing different categories of a categorical variable, such as letters in the alphabet. I then generated datasets from each of these distributions, varying the sample size between 2 and 30 and creating 10 different datasets for each sample size. This created 290 datasets for every unique distribution for each number of categories, or 26,100 datasets in total. For each dataset I calculated the naïve entropy of the sample and then applied the EESB to calculate the mean and 95\% confidence interval of the entropy for the parent population. The python code is included in the Supplementary Materials.

Rejecting samples whenever the population entropy estimate is greater than the maximum entropy $\log _{2} k$ of a typology of size $k$ does not catch all types of errors, but does preliminarily separate overly small samples from a mix of under-sampled and wellsampled distributions (Figure 2). As with most statistical testing, we can only reject the sample as not representative of the parent population at a given level of description-it is never possible to prove that the sample is definitively representative.

The EESB is a useful test for checking the relationship between a small dataset categorized according to some meaningful typology and whether the typology is a good descriptor of the overall material. I now turn to a hypothetical application that illustrates the problem of sparse empirical observations in archaeological urban studies.

\section{Demography and the Three Bears}

The EESB is useful because it allows us to reject a small sample and a typology when they cannot be representative of a parent population. This makes it possible to take a set of houses, assign them to types according to some useful typology, and assess whether our typology violates consistency between the sample and population if it were possible to apply the same typology to the parent population. Provided that they pass this basic test small samples can provide insight for settlements where few houses have been archaeologically documented.

For an example, let us consider the archaeological record of the fictional ancient city of Goldilockopoli. While once a large city, to archaeologists only three houses are known, known each as Casa Papa Bear, Casa Mama Bear, and Casa Baby Bear. According to a local archaeologist's typology, each of these belongs to its own particular type of dwelling: Casa Papa Bear is a good example of a large estate for an extended family, Casa Mama Bear is a typical house for a nuclear family, and Casa Baby Bear is just right for a single individual. Based on this small sample of three houses, each in its own category, a naïve suggestion would be that one third of the households at Goldilockopoli were single resident units, one third were nuclear families, and one third were extended families.

To assess whether this sample is consistent with the unobserved population, we can run the EESB on our dataset (Table 2). As intuited for such a small and sparse sample, the results are discouraging: the EESB estimate of the parent population's entropy is higher than $\log _{2} 3$, which suggests that our sample is not consistent with a larger, unobserved population that can also be described using only three categories. Given the small sample size, the high parent population entropy estimate implies that we need to gather more data before attempting a further demographic analysis.

The EESB provides a consistency check to assess how similar a small sample and a typology applied to it are to the inferred parent population. While future work will need to expand on how to best distinguish representative from non-representative samples, for now this can be done by comparing the estimated entropy with the maximum achievable value of a typology with $k$ categories, namely $\log _{2} k$, to reject a typology and sample as failing to capture the probable variability of the original system, requiring either a new typology, or more data. The simulated datasets demonstrated how sample rejection works in the abstract, while the toy study from Goldilockopoli showed how this method would reject a typology and sample as not accurately representing the parent population, making a specific study of households impossible for that city without more information.

With the use of the EESB in mind, I now turn back to the real case study, the city of Metapontum in southern Italy, where I will apply the bootstrap to rural houses occupied by urban households and demonstrate that they are a sample that appears to be consistent with the broader population of houses following two different typologies. Because of this, I will then proceed with a demographic calculation specific to Metapontum between the sixth and fourth centuries BCE as well as a discussion of potential implications for the study of the society at Metapontum. On this basis, I will propose an extension to existing urban demographic methods used in the Classical Mediterranean that can aid in the comparative study of ancient urbanism.

\section{RESULTS}

Applying the EESB to farmhouses at Metapontum according to a four-category architectural typology reveals that the synchronic view of the data bears the hallmarks of being a representative sample, namely the naïve entropy is close to the bootstrapped population entropy (Table 3). In particular, there are four observed categories in the present typology, and the maximum value for the entropy of a four-category typology is $\log _{2} 4=2$ bits, .1 bits greater than the expected entropy from the EESB. This suggests that it is not possible to reject our typology and sample as inconsistent with their inferred parent population. In short, the population entropy suggests that the typology used could accommodate the actual diversity of the countryside were more houses to be observed. A notable caveat is that the upper end of the $95 \%$ confidence interval is too high, and more statistical work will be required to construct precise tests of what thresholds should distinguish more representative from less representative samples. At minimum, this sample of 11 houses is internally consistent with the architectural diversity present in the ancient countryside. Otherwise, if the expected population entropy from the EESB had been $>2$ bits, it would indicate that our typology would need more categories to document the variability of the countryside, simultaneously indicating that the sample is too small or that the typology needs to be redefined. 


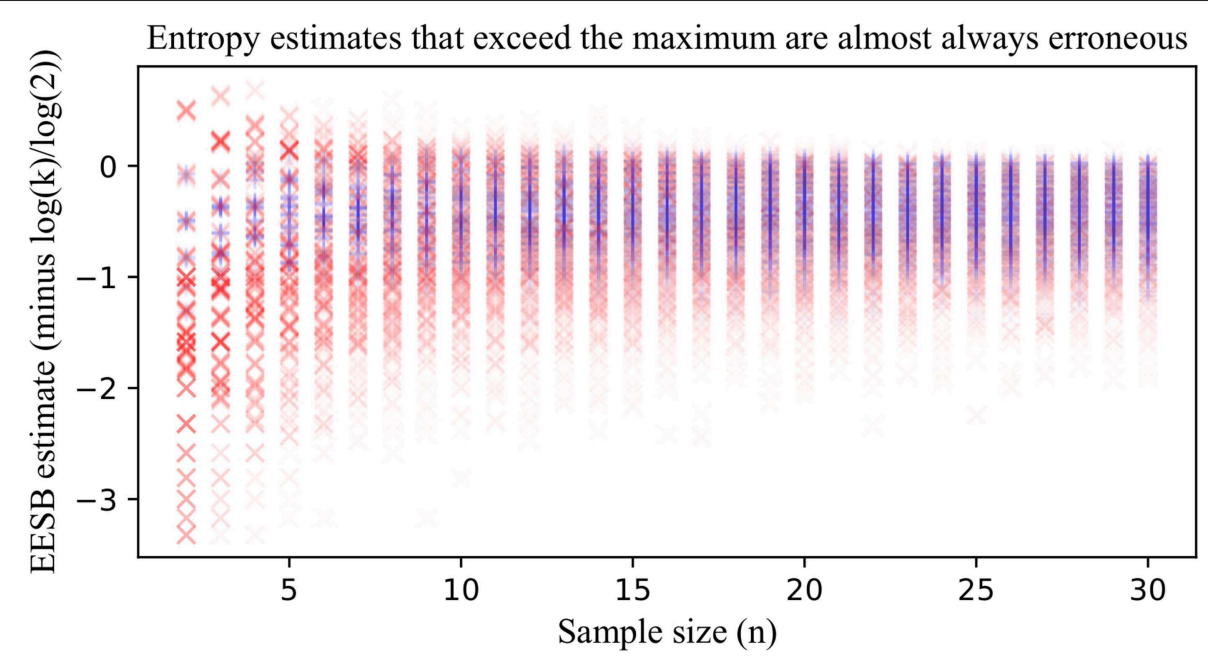

FIGURE 2 | From the simulated data experiment, the EESB estimated entropy minus the maximum entropy for the number of categories in that distribution is plotted against the sample size. All values $>0$ would be rejected following the recommendation proposed here to reject samples when the EESB entropy is $>$ log $2 k$. Blue plusses are used to represent samples where the EESB estimate was within $10 \%$ of the actual entropy of the source distribution, while a red $\mathrm{x}$ is used to represent samples $>10 \%$ of the actual entropy. Samples from low-entropy populations, namely those that are diverse with only a few common types, remain below the maximum entropy even when the sample size is too low to produce accurate estimates, and thus further criteria will be required in the future to distinguish representative and non-representative samples. High-entropy populations, namely those that are diverse, and have approximately equally common types, produce erroneously high estimates when under-sampled, making it easy to distinguish them from more representative samples.

TABLE 2 | EESB Estimates for Goldilocksopoli.

\begin{tabular}{lllll}
\hline Types & Houses & Naïve entropy & EESB entropy & 95\% CI EESB entropy \\
\hline 3 & 3 & 1.585 & 2.208 & $1.584-3.170$
\end{tabular}

The EESB entropy for the three houses at the fictional site of Goldilocksopoli is significantly higher than the naive entropy and the maximum entropy of a 3-category distribution $\left(\log _{2} 3=1.585\right)$, indicating that the sample is unlikely to be representative of a larger population if categorized by this typology.

TABLE 3 | Entropies for housing at Metaponto based on architectural features.

\begin{tabular}{lllll}
\hline Types & Houses & Naïve entropy & EESB entropy & 95\% CI EESB entropy \\
\hline 4 & 11 & 1.686 & 1.905 & $1.435-2.688$
\end{tabular}

The EESB entropy for the four-category architectural typology applied to rural housing at Metapontum is only slightly higher than the naive entropy and less than the maximum entropy of a 4-category distribution ( $\log _{2} 4=2$ ), which suggests that the houses are consistent with a representative sample from a larger distribution when categorized with this typology.

Similarly, the sample of documented rural farmhouses appears to be representative of the diversity present in the overall countryside when the farmhouses are categorized according to the number of buildings in each dwelling (Table 4). Here most houses consist of single structures, while only two farmhouses make use of multiple structures on the same plot. Both of these farmhouses also structure interactions through courtyards, which similarly provide the possibility of separating activities and individuals. The segmentation of space into multiple structures would be a supplemental organizational technology for households at Metapontum, rather than as essential as the use of a courtyard.
TABLE 4 | Entropies for housing at Metaponto based on number of buildings.

\begin{tabular}{lllll}
\hline Types & Houses & Naïve entropy & EESB entropy & 95\% Cl EESB entropy \\
\hline 3 & 11 & 0.8658 & 1.020 & $0.3831-1.732$ \\
\hline
\end{tabular}

The EESB entropy for rural housing at Metapontum categorized by the number of buildings composing each rural house is below the threshold for a three-category typology and only slightly above the naive entropy, which indicates that the rural houses are consistent with being a representative sample from a larger distribution when categorized with this typology.

Some of the variability present in the hinterland of Metapontum is diachronic, and partly the variation in farmhouses discussed here results from the changing social history of the town. Towers were not introduced until the second half of the fourth century BCE in the region, while the first courtyard house appeared in the sixth century BCE but saw few comparable structures until the fourth century BCE as well. If these architectural features are choices to facilitate privacy, oversight, or security, some inhabitants of the countryside changed their priorities through time, increasing the infrastructure implemented to control interactions compared with houses where these behaviors were not encoded in the layout of the house, although they could have been facilitated by more perishable means. As most comparative urban studies combine multiple periods of evidence in order to create larger sample sizes, I follow the same procedure here. I note, however, that chronologies are just a temporal form of typology in terms of our state of knowledge, and this same technique can be used to assess chronological representativeness or the intersection between a typology and the periods over which it is represented.

Since the EESB estimates indicate that our sample and its typology are structured like a representative sample, the material types described in the sample can be interpreted 
as representative of the population, facilitating demographic and social reconstructions of the broader urban population. Had the sample of rural housing failed this test, it would be irresponsible to continue without either adding more houses to the sample (likely at the loss of chronological or geographic specificity) or to consider a different typology that would be less sparsely documented. Instead, it is appropriate to interpret these data because of the certainty the EESB gives and move from documenting architectural diversity to interpreting the social and household diversity these material conditions partly shape and reflect, thus giving empirical basis to the study of the community at Metapontum.

\section{Demography, Inequality, and the Effects of Urbanism}

Demography in the Mediterranean world has largely relied upon homogenizing assumptions that all households are equal and can be treated interchangeably. These assumptions in part stem from Bagnall and Frier's (1994) work on the Roman census records from Egypt, yet their calculation of an average family size does not merit ignoring their variability. To the contrary, their analysis of the census data highlights the wide range of family and household sizes, their systematic variation with size of settlement, and the compounding effects of household lifecycles on calculating meaningful household statistics (Bagnall and Frier, 1994, p. 53-74).

While architectural typologies fail to capture the full range of unique characteristics that distinguish houses and their occupant households, socially-informative features such as those proposed above can inform our reconstructions of household demography. If courtyards are more frequent when issues of privacy and observation are important, it is not unreasonable to infer that larger families and more household slaves and servants were foreseen, even if never realized. If towers are a correlate of wealth, and either a direct or indirect correlate of agricultural landholding and increased numbers of enslaved persons, then their presence may indicate a still greater household population. Compared to smaller single-structure farmhouses, there is a clear spectrum here of expected populations in different types of houses when a household builds a given house. A blanket average does reconstructions of the social life of Metapontum little justice, particularly given the demographic importance of including slaves and non-kin dependents into calculations of community populations (Storey, 2001, 2002).

Given the range of population estimates in the Greco-Roman world for households, we can begin to piece together some estimates for household co-resident groups at Metapontum during the sixth through third centuries. Six of the eleven houses had neither a courtyard nor a tower. If those are indeed markers of greater wealth and particular priorities concerning privacy and security, then these other houses either encoded similar ideas in less permanent means, or did not have the interest or ability to encode those priorities in the architecture. These may then be smaller or less well-off farmers, although they are unlikely to be poor (Pettegrew, 2001; Winther-Jacobsen, 2010). Bagnall and Frier (1994, p. 67-8) calculate an average family size of slightly less than five without including any slaves or non-kin members. This is an average over a variety of household forms, ranging from single residents to large multiple family households. If it were possible to better relate the material record with particular household forms, this average could be updated. Given that these houses likely were not constructed for or by poor families, it would fit their demographic reconstructions to include at least one slave and occasionally a lodger, bringing an estimate to around 6 for the least architecturally elaborated of the houses in our sample.

The remaining five houses had some form of courtyard, which may indicate that half of households needed to oversee interactions and regulate the movements of individuals within the house. This serves both as an indication of wealth, such that this family has the ability to carry out more stringent performances of gender and status roles, and of the size of the household, namely that multiple dependents, servants, or slaves would have been present. Bagnall and Frier note that in villages, household size, wealth, and the number of different types of family members cohabiting are tightly correlated, whereas in metropoleis the correlation is not as clear, and smaller families may be preferred by wealthier households; however, this difference is more than made up for by the greater numbers of slaves and non-kin lodgers or renters such that more urban households tend to be larger (Bagnall and Frier, 1994, p. 71). Such an assumption would make the average household size for this group closer to 7.5 .

Out of those houses with a courtyard, one also has a tower, which may be a marker of even more extreme wealth and potentially connected to the deployment of large agricultural workforces. Morris and Papadopoulos (2005) propose that the ancient Greek mode of agriculture would rarely have used groups of slaves larger than 10 people, and so a reasonable estimate would be half of that slave population, or 9.5 persons on average. It is possible that some of these people lived outside of the estate, but the extent to which this occurred is not presently known, and likely a good target for future work.

Our representative sample of rural housing at Metapontum provides new ways to think about ancient urban communities based on the observed properties of excavated houses. The consideration of social diversity makes it possible to ask questions about systematic relationships between status, wealth, household organization, and demography as well as their frequency at individual communities in an empirically grounded manner. If we wish to calculate an average household size, it is still possible to calculate that 6.86 people are estimated to live in each house (Table 5). Considering the relationship between individuals and households, however, emphasizes the variable experiences typical of different classes and statuses within the population.

Should we wish to think about the average size of household that a person lives in, we would note that the average person lives in a household with 7.04 people, as more people live in the larger households and most households are large. Typical lodgers, slaves, and other members of the household external to the family live in an even larger household with an average of 7.54 people per household because of the tendency for larger, wealthier households to own more slaves and have the facilities for more lodgers. Incorporating variability and social diversity into demographic reconstructions extends beyond deriving a single average across all households, and instead makes 
TABLE 5 | Demographic calculations for Metaponto.

\begin{tabular}{|c|c|c|c|c|c|}
\hline House type & Avg. family size & Avg. non-family size & Avg. household size & Number of houses & Expected number of people \\
\hline No courtyard & 5 & 1 & 6 & 6 & 36 \\
\hline Courtyard, central & 4.5 & 3 & 7.5 & 2 & 15 \\
\hline \multirow[t]{2}{*}{ Courtyard with tower } & 4.5 & 5 & 9.5 & 1 & 9.5 \\
\hline & & & & Average people in sample & 75.5 \\
\hline
\end{tabular}

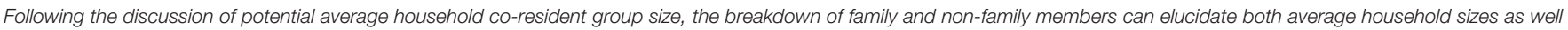
as variation in co-resident groups. Here average family size is added to the average non-family size to derive an average household co-resident group size for each type of house, assuming an average over household forms. These can then be multiplied by the number of houses observed to calculate the expected number of people living in each type of house, which in turn reflects the average household size for those houses in this sample.

it feasible to address more complex associations traditionally near the heart of anthropological household archaeology (Wilk and Rathje, 1982).

The record of local housing enables a deep probing of urban social networks and society. Even small samples of housing can be analyzed to define specific demographic distributions for individual cities based on comparanda that relate architectural and social diversity. Further forms of material evidence and a greater breadth of comparative frameworks can be used to analyze these small groups of households and fruitfully investigate social diversity. With this method and small datasets like the rural houses of Metapontum in mind, I would now like to turn to some applications of the EESB to studies of ancient urbanism.

\section{DISCUSSION}

Empirically studying the material remains of households, even when scantily preserved, directly impacts comparative archaeological studies of urbanism. Almost all studies of archaeologically documented urbanism rely on sites like Metapontum for the majority of their case studies, where an extensive publication record in English and a decadeslong research program facilitate its inclusion in Englishbased comparative studies. Metapontum itself frequently merits inclusion in quantitative urban demographic studies of the Classical Mediterranean because some basic statistics of the city's grid have been made accessible. Hansen (2006b) calculated the average urban house size as $215 \mathrm{~m}^{2}$ for his study of the demography of the Greek political system, while Hanson and Ortman (2017) calculated a total density of 214 people per ha based on Carter (2006) estimate of around 3,000 houses in 70 ha for their study of urban scaling. It is this last study of urban scaling I wish to focus on in considering the impact of empirical methods for the study of households.

Urban scaling, a theoretical framework that applies scaling principles from physics to the study of human social forms, has postulated mechanisms that link diverse, daily social interactions within the built environment of cities to community-level properties like productivity, crime rates, energy consumption, and infrastructure expenditures for the modern world (Bettencourt, 2013). Empirical studies and theory have identified that social outcomes such as productivity, innovation, and crime grow faster than population growth because of the canalizing effects of urban infrastructure on social interactions, while densification and reduced per-capita infrastructure enable increasing efficiencies as cities grow (Bettencourt, 2013). Most urban measurements thus grow non-linearly with respect to population size. Some, such as productivity, increase superlinearly, such that per capita economic output increases through time. Others increase sub-linearly, such that the miles of streets per capita decreases as a city's population grows. Moreover, the framework provides the scaffolding to construct other models of social interaction and compare their outcomes at the scale of cities, testing whether community-level differences in measurable properties can emerge from differences in modes of social interaction at the scale of small groups (Bettencourt and Lobo, 2016; Cesaretti et al., 2016). Social variability must be explicitly documented, studied, and incorporated into regional studies of urbanism in order for urban scaling to have explanatory power. Unfortunately, in most regions few archaeological sites have sufficient thoroughly-investigated and well-published houses to provide even a dozen examples out of the thousands of houses that were likely built over the history of a given community.

Archaeologists have recognized the potential applicability of this theory to explaining the effects of agglomeration, and archaeological data have proved useful in testing the range of its predictions (Ortman and Coffey, 2017). Archaeological studies of scaling have encountered problems with correlated proxies, however, which confound the expected effects of scaling and introduce linear relationships between variables into our search for non-linearity (Bettencourt et al., 2013; Ortman et al., 2014, 2015) Statistically, filling in missing details about individuals and small groups with average values imposes linear models on our data. For studies of urban demography, assuming an average number of people per household for every settlement assumes that the size of household co-resident groups is invariable as a settlement grows larger, masking potential urban scaling effects.

The primary phenomenon to be explained by urban scaling is diversity, as the theory takes a staggering array of social forms, communal practices, individual identities, and 
material expressions that cities play host to and identifies shared, explanatory commonalities. Studying urban scaling thus requires more empirical data about variation within and between communities, one of the original goals of household archaeology (Willey, 1982). For sites where urban housing is available, techniques assessing the representativeness of small samples such as the EESB can help further empirically ground studies of urban scaling by providing settlement-specific views of household heterogeneity, sizes of co-resident groups, and potential implications for urban social networks. Hanson and Ortman's (2017) study of urban scaling in the Classical Mediterranean already noticed this, and they have moved the research program in a more empirically-grounded direction by incorporating information on a site-by-site level rather the application of regional rules as in previous demographic studies of the Aegean (Muggia, 1997; Hansen, 2006b, 2008). For the study of individual cities and the untangling of their tightly-correlated developmental trajectories that tie together area, population, wealth, and resource consumption, it is necessary to break down our data to the smallest empirical analytical units possible, as homogeneity confounds our object of study. Hanson and Ortman (2017) have already proposed and implemented one means of doing this, and I hope the present work will be an extension to assess how we can use small datasets of houses and other sparsely excavated material entities to expand our knowledge of ancient cities.

Empirical techniques for the study of ancient cities can be nested and extended to make the most of what limited datasets exist. Assumptions at this stage are then made more explicit and are framed at a level closer to the lived social diversity of the cities we wish to study. Step by step, our models move from ideal to real ideal, wherever possible exploiting small samples and scattered material to bring out the true richness of ancient urbanism.

\section{REFERENCES}

Adamesteanu, D. (1970). "L’attivitá archeologica in basilicata," in Atti del Convegno di Studi Sulla Magna Grecia (Napoli: Arte Tipografica), 467-486.

Adamesteanu, D. (1973). "Le suddivisioni di terra nel Metapontino," in Problèmes de la Terre en Grèce Ancienne, ed M. I. Finley (Paris: Mouton and Co), 49-61.

Bagnall, R. S., and Frier, B. W. (1994). The Demography of Roman Egypt. Cambridge: Cambridge University Press.

Benco, N. L. (1989). "Diversity in ceramic production: a case study from medieval north africa," in Medieval Archaeology: Papers of the Seventeenth Annual Conference of the Center for Medieval and Renaissance Studies, Medieval \& Renaissance Texts \& Studie 60, ed C. L. Redman (Binghamton, NY: State University of New York Press), 97-118.

Bettencourt, L. M., Cabaniss, A. H. F., and Ortman, S. G. (2013). Evidence of Urban scaling in prehispanic central Mexico. Santa Fe Institute Working Paper, 13-01-001.

Bettencourt, L. M., and Lobo, J. (2016). Urban scaling in Europe. J. R. Soc. Interface 13:20160005. doi: 10.1098/rsif.2016.0005

Bettencourt, L. M., Lobo, J., Strumsky, D., and West, G. (2010). Urban scaling and its deviations: revealing the structure of wealth, innovation and crime across cities. PLoS ONE 5:e13541. doi: 10.1371/journal.pone.0013541

Bettencourt, L. M. A. (2013). The origins of scaling in cities. Science 340, 1438-1441. doi: 10.1126/science. 1235823

Carter, J. C. (1980). A classical landscape: rural archaeology at Metaponto. Archaeology 33, 23-32.

\section{AUTHOR CONTRIBUTIONS}

AC designed, implemented, interpreted, and wrote the study.

\section{FUNDING}

This paper was published thanks to OPEN-AIRE funding granted to Francesca Fulminante for the Marie Sklodowska IEF PastPeople-Nets 628818 conducted at the University of Roma Tre (2014-2016). This research was partially supported by the University of Michigan.

\section{ACKNOWLEDGMENTS}

Part of this paper was first written for Lisa Nevett's graduate seminar on domestic space in the Greco-Roman world, and was subsequently presented at the Computer Applications and Quantitative Methods in Archaeology (CAA) international conference in Atlanta, GA, in 2017. I would like to thank the other students in that class as well as the audience at CAA for their discussion and input into this method. Thanks to Lisa Nevett and Sheira Cohen for reading over drafts of this work. Thanks also to Francesca Fulminante for her essential support. I would also like to thank the three reviewers whose recommendations have substantially improved the clarity and content of this paper. Any errors that remain are exclusively my own.

\section{SUPPLEMENTARY MATERIAL}

The Supplementary Material for this article can be found online at: https://www.frontiersin.org/articles/10.3389/fdigh. 2019.00011/full\#supplementary-material

Carter, J. C. (1981). "Rural settlement at Metaponto," in Archaeology and Italian Society: Prehistoric, Roman and Medieval Studies II, eds G. Barker and R. Hodges (Oxford: BAR), 167-178.

Carter, J. C. (1990). "Metapontum - land, wealth, and population," in Greek Colonies and Native Populations, ed J. P. Descoedres (Oxford: Clarendon Press), 405-441.

Carter, J. C. (2006). Discovering the Greek Countryside at Metaponto. Ann Arbor, MI: University of Michigan Press.

Carter, J. C. (2011). "Introduction," in The Chora of Metaponto 3: Archaeological Survey Bradano to Basento, eds J. C. Carter and A. Prieto (Austin, TX: University of Texas Press), 17-25.

Carter, J. C., and Prieto, A. (eds.). (2011). "Prolegomena to the settlement of the chora," in The Chora of Metaponto 3: Archaeological Survey Bradano to Basento (Austin, TX: University of Texas Press), 559-639.

Cesaretti, R., Lobo, J., Bettencourt, L. M. A., Ortman, S. G., and Smith, M. E. (2016). Population-area relationship for medieval european cities. PLoS ONE 11:e0162678. doi: 10.1371/journal.pone.0162678

De Siena, A. (2001). "Profilo storico archeologico", in Metaponto: archeologia di una colonia greca, ed A. De Siena (Taranto: Scorpione Editrice), 7-44.

De Siena, A. (2005). Tramonto della Magna Grecia: la documentazione archeologica dai territori delle colonie greche di Metaponto e Herakleia. Atti del Convegno di Studi Sulla Magna Grecia 44, 433-458.

De Siena, A., and Giardino, L. (2001). "Trasformazione delle aree urbane e del paesaggio agrario in età romana nella basilicata sudorientale," in 
Modalità Insediative e Strutture Agrarie nell'Italia Meridionale in Età Romana (Bari: Edipuglia), 197-211.

DeDeo, S. (2013). THOTH. Available online at: http://thoth-python.org/ (accessed April 30, 2019).

DeDeo, S., Hawkins, R. X. D., Klingenstein, S., and Hitchcock, T. (2013). Bootstrap methods for the empirical study of decision-making and information flows in social systems. Entropy 15, 2246-2276. doi: 10.3390/e150 62246

Dickens, R. S., and Fraser, M. D. (1984). An information-theoretic approach to the analysis of cultural interaction in the middle woodland period. Southeast. Archaeol. 3, 144-152.

Foxhall, L. (2009). "Gender," in A Companion to Archaic Greece, Blackwell Companions to the Ancient World 196. eds K. A. Raaflaub and H. V. Wees (Chichester; Malden, MA: Wiley-Blackwell), 483-507.

Giannotta, M. T. (1980). Metaponto ellenistico-romano: problemi topografici. Galatina: Congedo Editore.

Hansen, M. H. (2006a). Polis : An Introduction to the Ancient Greek City-State. Oxford: Oxford University Press.

Hansen, M. H. (2006b). The Shotgun Method: The Demography of the Ancient Greek City-State Culture. Columbia, SC: University of Missouri.

Hansen, M. H. (2008). An update on the shotgun method. Greek Roman Byzantine Stud. 48, 259-286.

Hanson, J. W., and Ortman, S. G. (2017). A systematic method for estimating the populations of Greek and Roman settlements. J. Roman Archaeol. 30, 301-324. doi: 10.1017/S1047759400074134

Jameson, M. H. (1990). "Domestic space in the greek City-state," in Domestic Architecture and The Use of Space: An Interdisciplinary Cross-Cultural Study, ed S. Kent (Cambridge: Cambridge University Press), 92-113.

Justeson, J. S. (1973). Limitations of archaeological inference: an informationtheoretic approach with applications in methodology. Am. Antiquity 38, 131-149. doi: $10.2307 / 279360$

Kent, S. (1990). "A cross-cultural study of segmentation, architecture, and the use of space," in Domestic Architecture and the Use of Space: An Interdisciplinary Cross-Cultural Study, ed S. Kent (Cambridge; New York, NY: Cambridge University Press), 127-152.

Kintigh, K. W. (1984). Measuring archaeological diversity by comparison with simulated assemblages. Am. Antiquity 49, 44-54. doi: 10.2307/ 280511

Kramer, C. (1982). Ethnographic households and archaeological interpretation: a case from Iranian Kurdistan. Am. Behav. Sci. 25, 663-675. doi: 10.1177/000276482025006005

Lanza Catti, E., Swift, K., and Carter, J. C. (2014a). The Chora of Metaponto 5: A Greek Farmhouse at Ponte Fabrizio. Austin, TX: University of Texas Press.

Lanza Catti, E., Swift, K., and Limoncelli, M. (2014b). "Farmhouse structure and plan," in The Chora of Metaponto 5: A Greek Farmhouse at Ponte Fabrizio, eds E. L. Catti, K. Swift, and J. Coleman Carter (Austin, TX: University of Texas Press), 83-110.

Llewellyn-Jones, L. (2007). "House and veil in ancient greece," in Building Communities: House, Settlement and Society in the Aegean and beyond: Proceedings of a Conference Held at Cardiff University, 17-21 April 2001, 251-58. British School at Athens Studies 15. British School at Athens.

Mertens, D. (1999). "Metaponto: L'evoluzione del centro urbano," in Storia della Basilicata 1, L'Antichità, ed D. Adamesteanu (Bari: Edition Laterza), 247-294.

Morris, S. P., and Papadopoulos, J. K. (2005). Greek towers and slaves: an archaeology of exploitation. Am. J. Archaeol. 109, 155-225. doi: 10.3764/aja.109.2.155

Muggia, A. (1997). L'area di rispetto nelle colonie magno-greche e siceliote. Palermo: Sellerio editore.

Nava, M. L. (2002). L'attività archeologica in Basilicata nel 2001. Atti del Convegno di Studi Sulla Magna Grecia 41, 719-765.

Nevett, L. C. (1994). "Separation or seclusion? towards an archaeological approach to investigating women in the greek household in the fifth to third centuries BC," in Architecture and Order: Approaches to Social Space, eds M. P. Pearson and C. Richards (London; New York, NY: Routledge), 98-112. doi: 10.4324/9780203401484_chapter_5
Nevett, L. C. (1999). House and Society in the Ancient Greek World. Cambridge: Cambridge University Press.

Nevett, L. C. (2005). "Between urban and rural: house-form and social relations in attic villages and deme centers," in Ancient Greek Houses and Households: Chronological, Regional, and Social Diversity, eds Bradley A. Ault and Lisa C. Nevett (Philadelphia, PA: University of Pennsylvania Press), 83-98. doi: $10.9783 / 9780812204438.83$

Nevett, L. C. (2007a). "Domestic architecture and household wealth: the case of ancient greece," in The Durable House: House Society Models in Archaeology, ed Robin A. Beck (Carbondale, IL: Center for Archaeological Investigations), 365-379.

Nevett, L. C. (2007b). "Greek houses as a source of evidence for social relations," in Building Communities: House, Settlement and Society in the Aegean and beyond: Proceedings of a Conference Held at Cardiff University, 17-21 April 2001, eds Ruth C. Westgate and J. Whitley, 5-10. British School at Athens Studies 15. British School at Athens.

Notario, C. (2001). "Saldone di metaponto," in Bibligorafia topografica della colonizzazione greca in Italia e nelle isole tirreniche, eds G. Nenci and G. Vallet (Naples: Scuola Normale Superiore and Ecole Française de Rome Centre J. Berard), 201-205.

Ortman, S. G., Cabaniss, A. H. F., Sturm, J. O., and Bettencourt, L. M. A. (2014). The pre-history of urban scaling. PLoS ONE 9:e87902. doi: 10.1371/journal.pone.0087902

Ortman, S. G., Cabaniss, A. H. F., Sturm, J. O., and Bettencourt, L. M. A. (2015). Settlement scaling and increasing returns in an ancient society. Sci. Adv. 1:e1400066. doi: 10.1126/sciadv.1400066

Ortman, S. G., and Coffey, G. D. (2017). Settlement scaling in middle-range societies. Am. Antiquil. 82, 662-682. doi: 10.1017/aaq.2017.42

Osanna, M. (1992). Chorai coloniali da Taranto a Locri: documentazione archeologica e ricostruzione storica. Rome: Instituto Poligrafico dello Stato.

Pettegrew, D. K. (2001). Chasing the classical farmstead: the formation and signature of rural settlement in greek landscape archaeology. J. Mediter. Archaeol. 14, 189-209. doi: 10.1558/jmea.v14i2.189

Schojer, T. (2001a). Ginosa marina (Taranto). Taras 21, 124-126.

Schojer, T. (2001b). Il N.W. Tarantino. Atti del Convegno di Studi Sulla Magna Grecia 41 [3 (Tavola Rotonda)], 65-86.

Schojer, T. (2003). Ginosa Marina (Taranto), Pantano. Taras 23, 242-244.

Shannon, C. E. (1948). A mathematical theory of communication. Bell Syst. Tech. J. 27, 379-423. doi: 10.1002/j.1538-7305.1948.tb01338.x

Storey, G. R. (2001). Regionaries-type insulae 1: architectural/residential units at Ostia. Am. J. Archaeol. 105, 389-401. doi: 10.2307/507362

Storey, G. R. (2002). Regionaries-type insulae 2: architectural/residential units at Rome. Am. J. Archaeol. 106, 411-434. doi: 10.2307/4126281

Uggeri, G. (1969). Kleroi arcaici e bonifica classica nella chora di Metaponto. La Parola del Passato CXXIV, 51-71.

Westgate, R. C. (2015). Space and social complexity in Greece from the Early Iron Age to the Classical period. Hesperia 84, 47-95. doi: 10.2972/hesperia.84.1.0047

Wilk, R. R., and Rathje, W. L. (1982). Household archaeology. Am. Behav. Sci. 25, 617-639. doi: 10.1177/000276482025006003

Willey, G. R. (1982). Foreword. Am. Behav. Sci. 25, 613-616. doi: $10.1177 / 000276482025006002$

Winther-Jacobsen, K. (2010). The classical farmstead revisited. Activity differentiation based on a ceramic use-typology. Ann. Br. School Athens 105, 269-290. doi: 10.1017/S0068245400000411

Conflict of Interest Statement: The author declares that the research was conducted in the absence of any commercial or financial relationships that could be construed as a potential conflict of interest.

Copyright (C) 2019 Cabaniss. This is an open-access article distributed under the terms of the Creative Commons Attribution License (CC BY). The use, distribution or reproduction in other forums is permitted, provided the original author(s) and the copyright owner(s) are credited and that the original publication in this journal is cited, in accordance with accepted academic practice. No use, distribution or reproduction is permitted which does not comply with these terms. 